\title{
Paleomagnetic Study of Deccan Traps from Jabalpur to Amarkantak, Central India
}

\author{
R.K. Verma, ${ }^{*}$ G. Pullaiah, ${ }^{* *}$ G.R. Anjaneyulu \\ National Geophysical Research Institute, Hyderabad, \\ and \\ P.K. MALLIK \\ Indian School of Mines, Dhanbad
}

(Received July 13, 1973; Revised September 17, 1973)

\begin{abstract}
Results of paleomagnetic studies of twenty-four flows sampled from the area between Jabalpur $\left(23^{\circ} 11^{\prime} \mathrm{N}, 77^{\circ} 58^{\prime} \mathrm{E}\right)$ and Dindori $\left(22^{\circ} 57^{\prime} \mathrm{N}, 81^{\circ} 00^{\prime} \mathrm{E}\right)$ in the northeast part of the Deccan trap exposure are presented. The elevations of the flows varied from $372 \mathrm{~m}$ to $670 \mathrm{~m}$ above mean sea level. The results reveal the presence of a field reversal quite different from the one studied by earlier workers. Presence of this field reversal has been recently indicated by PAL et al. and Wensink, in the Malwa and Nagpur regions, respectively. A comparison of the paleomagnetic results of the Deccan volcanics from different areas with those of normal polarity from Jabalpur-Dindori region indicates that the land mass of India drifted northward by about $21^{\circ}$ during the entire period of the igneous activity represented by the Deccan traps.
\end{abstract}

\section{Introduction}

During the past two decades, paleomagnetism of Deccan volcanics (commonly known as traps) has been studied in a large number of locations fairly wide spread over the entire exposure of the Deccan traps (CLEGG et al., 1956; Deutsch et al., 1959; Sahsrabudhe, 1963; Bhimasankaran and Pal, 1968; Pal et al., 1971; Athavale, 1970; Athavale and Anjaneyulu, 1971; Wensink and Klootwijk, 1971; Verma and Pullaiah, 1971; Verma and Mital, 1972; Kono et al., 1972; Verma and Mital, 1973). Figure 1 shows the locations where the traps have been studied so far.

Ever since the paleomagnetic studies of the Deccan traps were initiated in India in 1953 at the Tata Institute of Fundamental Research, Bombay, interest has been mainly centered on obtaining evidence in support of continental drift

\footnotetext{
Present address:

* Indian School of Mines, Dhanbad, Bihar, India

** Geomagnetic Division, Earth Physics Branch, Department of Energy, Mines and Resources, Ottawa, Canada
} 


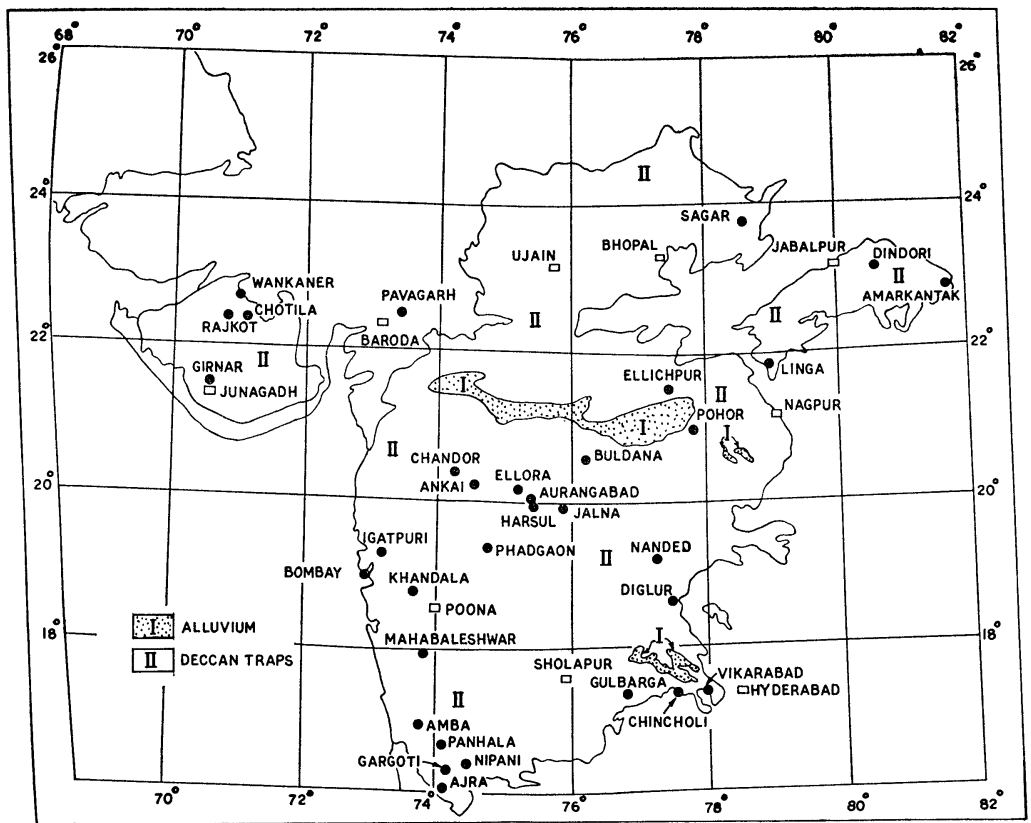

Fig. 1. Locations of sites from where Deccan traps have been studied so far.

of the Indian land mass. Recent discovery of the hypothesis of sea floor spreading has focussed attention on periodic field reversals during the geologic past particularly during the Cretaceous to Recent periods. Hence, the interest in the study of field reversals during Cretaceous as recorded in the Deccan traps as well.

After the initial studies on the Deccan traps mostly from the Western Ghats by Deutsch et al. (1959), it was established that the geomagnetic field reversed its polarity from reverse to normal during the period of these volcanic eruptions. This field reversal was found to be located near an elevation of $610 \mathrm{~m}$ above sea level. Recent studies by several workers (Bhimasankaram and PaL, 1968; Pal et al., 1971; Athavale 1970; Verma and Mital, 1972, 1973) have established that this field reversal is located at different elevations in different areas. Bhimasankaram and PAL (1968) and Pal et al. (1971) from their studies in Aurangabad and Chandor areas have suggested that perhaps more than one field reversal took place during the entire period of the Deccan trap igneous activity.

The study of field reversal in the Deccan traps is an important geophysical problem for purposes of reconstructing Mesozoic paleomagnetic stratigraphy. Recent construction of paleomagnetic stratigraphy for the Mesozoic by McElhinny and Burek (1971) and Pecherski (1970) indicate that the duration of some of the field polarities during the Cretaceous has been as much as $20 \mathrm{~m}$.y. as compared to less than one m.y. for the period recent to $5 \mathrm{~m} . \mathrm{y}$. BP. (Cox 1969). 
Detailed paleomagnetic studies of Deccan traps can be help us to clarify several details of Cretaceous paleomagnetic stratigraphy.

In this paper evidence supporting a second field reversal observed in the Deccan traps, different from the first well-known field reversal is presented. This evidence has been obtained from the study of Deccan traps from the area of Jabalpur to Amarkantak in the northeast part of the main Deccan trap exposure. On the basis of paleomagnetic studies, the igneous activity in this area is correlated with that from other parts of the Deccan trap area. An estimate of the continental drift of the subcontinent of India during the entire period of Deccan trap eruptions is given.

\section{Sampling}

Paleomagnetic sampling of the traps was made in the area between Jabalpur $\left(23^{\circ} 11^{\prime} \mathrm{N}, 79^{\circ} 58^{\prime} \mathrm{E}\right)$ and Dindori $\left(22^{\circ} 57^{\prime} \mathrm{N}, 81^{\circ} 06^{\prime} \mathrm{E}\right)$ situated in the northeast part of the main Deccan traps. Earlier Verma and Pullaiah (1971) reported results of paleomagnetic studies of eleven flows (sites 1 to 11) from localities between approximately $80^{\circ} 30^{\prime}$ to $81^{\circ} \mathrm{E}$ and $23^{\circ} \mathrm{N}$ in the same general area. Athavale (1970) studied eighteen flows ranging in elevation from $715 \mathrm{~m}$ to $1015 \mathrm{~m}$ in the area between Dindori and Amarkantak $\left(22^{\circ} 40^{\prime} \mathrm{N}, 81^{\circ} 42^{\prime} \mathrm{E}\right)$.

Hand-oriented samples from twenty-four different sites, numbered 12 to 35 with 5 to 10 samples from each site were collected in the area between Jabalpur to Dindori. Samples for sites $15,16,17,18,25,16,30$ were collected on a

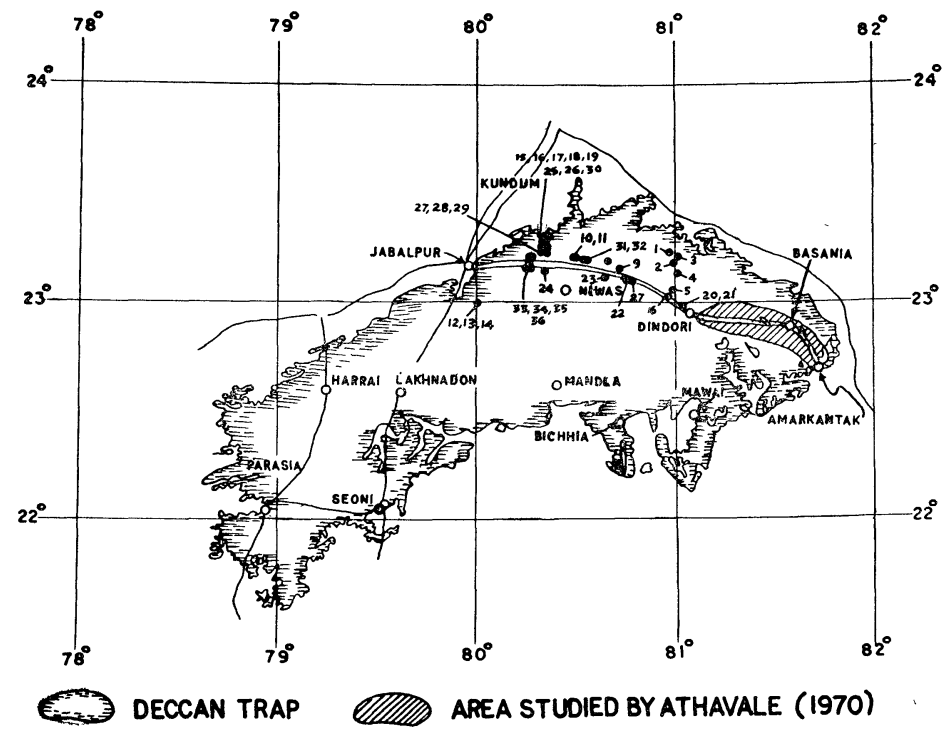

Fig. 2. Detailed locations of sampling sites of Deccan trap between Jabalpur and Amarkantak for which results are reported in this paper. 
hill along the cutting of the Hiran Nadi river near the village Kundam. Sites 28,29 are located on the same hill within a short distance of above-mentioned sites. Sites 22, 23, 24 are located along Jabalpur-Dindori highway east of Kundam. The locations of sampling sites are shown in Fig. 2. The elevations of these sites were determined using microaltimeter and topographic maps of the Survey of India. The elevations varied from 372 to $670 \mathrm{~m}$. The samples were studied in the paleomagnetic laboratory of the National Geophysical Research Institute at Hyderabad using an astatic magnetometer of sensitivity $3 \times$ $10^{-6} \mathrm{Oe} / \mathrm{cm}$ deflection.

\section{Stability Tests}

In order to remove unstable components of Natural Remanent Magnetization, samples were demagnetized in steps of 50,100, $150 \mathrm{Oe}$. peak fields using an a.f. demagnetizer similar to that of CREER (1959). Typical decay curves of normalised intensity for a few samples are shown in Fig. 3.

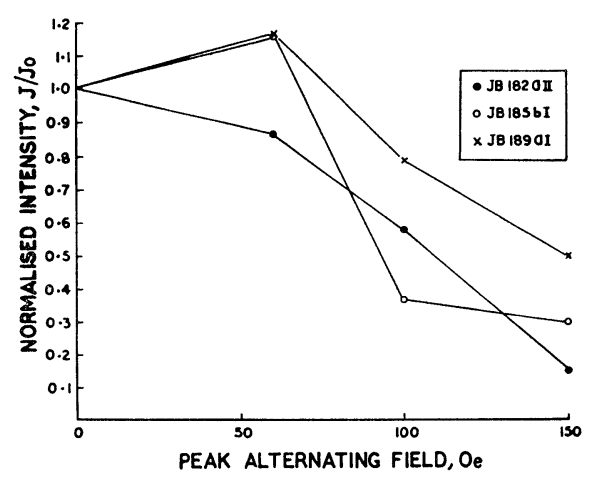

Fig. 3. A.F. demagnetization curves of normalized intensity for few representative samples.

Most of the sites revealed stable directions of magnetization upon af cleaning in fields varying from 50 to 150 Oe. Sites $25,26,29$ and 33 showed scattered directions with large variation in declination and inclinating, the rocks from the same site showing normal, intermediate as well as reverse directions. These could not be cleaned adequately using the demagnetization apparatus. Hence results from these sites were rejected.

\section{Results and Discussion}

Mean directions of magnetization of all the flows after af demagnetization are listed in Table 1 along with other paleomagnetic parameters. The mean directions of flows presently studied are plotted in Fig. 4 along with the results 
Paleomagnetic Study of Deccan Traps from Jabalpur to Amarkantak, Central India 441

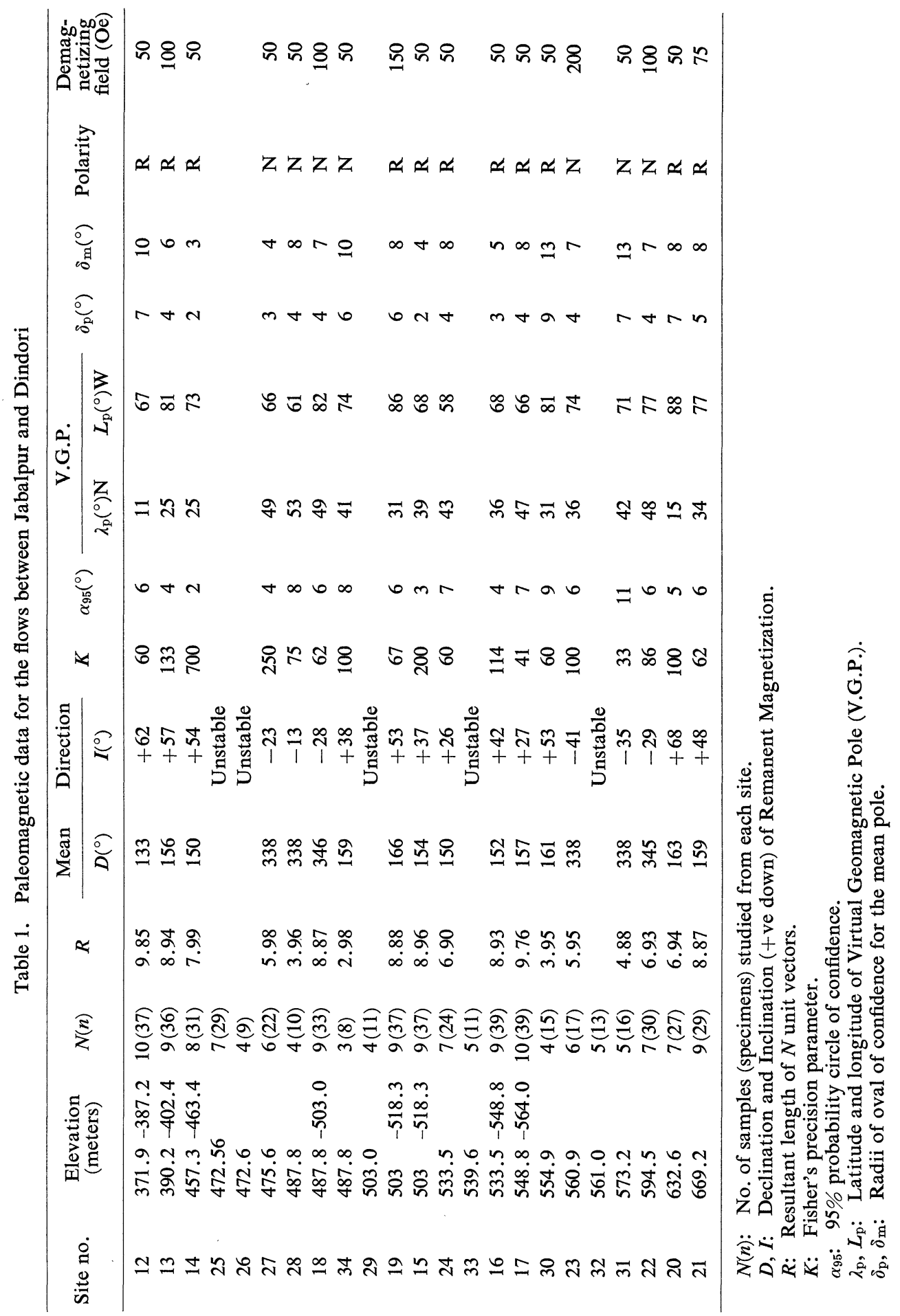




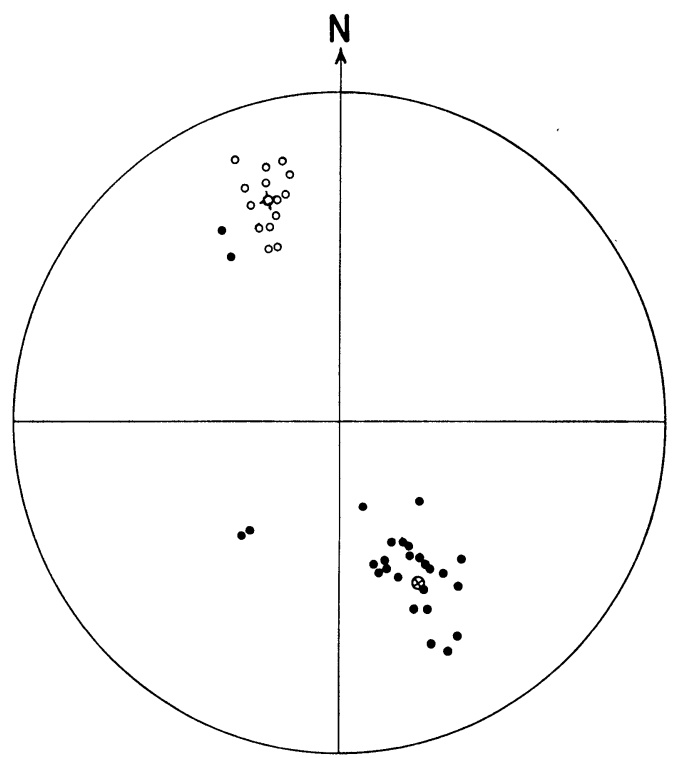

Fig. 4. Mean directions of flows presently studied, along with those studied by Verma and Pullaiah (1971) for nine flows and Athavale (1970) from Dindori and Amarkantak area. - - indicates mean directions of flows with normal polarity and $\otimes$ indicates reverse polarity.

of earlier studies by Verma and Pullaiah (1971) for nine flows in the same area and Athavale (1970) for flows in Dindori to Amarkantak area. The earlier studies by these authors had shown that rocks with normal polarity were lying between elevation of $656 \mathrm{~m}$ to $885 \mathrm{~m}$ in the area near Dindori and above $982 \mathrm{~m}$ in the area near Amarkantak. The underlying rocks were found to have reverse polarity.

The important result of the present study is the discovery of a new field reversal as shown in Fig. 5. It is important to note that the flows no. 15, 16, $17,18,19,25,26,27,28,30$ showing the field reversal have been sampled only from one locality near Kundam on a hill. Flows 18, 27 and 28 showing normal polarity are underlying flows $15,16,17$ and 19 showing reverse polarity in the section studied.

It has been generally observed that in most areas of the Deccan traps large thickness of flows with normal polarity overlie those with reverse polarity. Here in the area between Jabalpur to Dindori, the field reversal is in the opposite sense as shown.

Recently PAL et al. (1971) also found evidence of normal rocks underlying those with reverse polarity in Malwa Plateau near an elevation of about $330 \mathrm{~m}$. Similar evidence has also been obtained by WeNsink (1973) in Central India at locations near Pohor and Ellichpur. The field reversal in this area appears to 


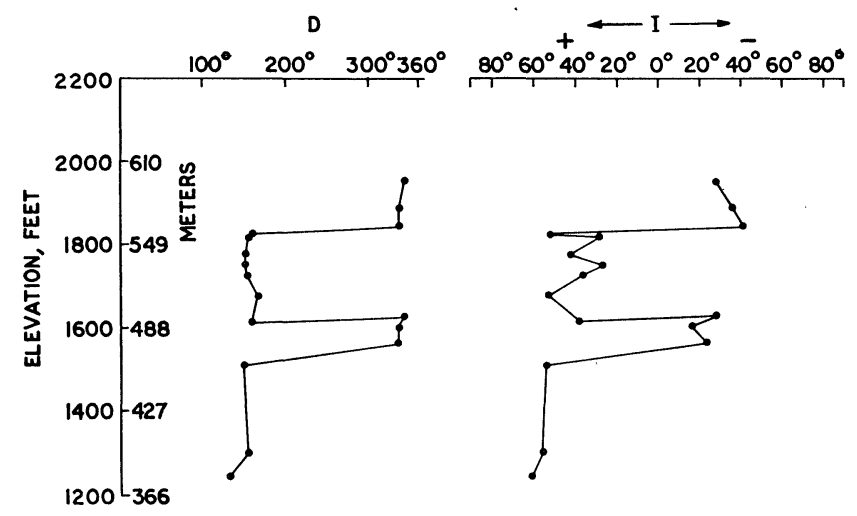

Fig. 5. Change in declination and inclination of flows No. 15, 16, 17, 18, 19, 25, 26, 27, 28, 29, 30 from a site near Hiran Nadi which indicates a field reversal.

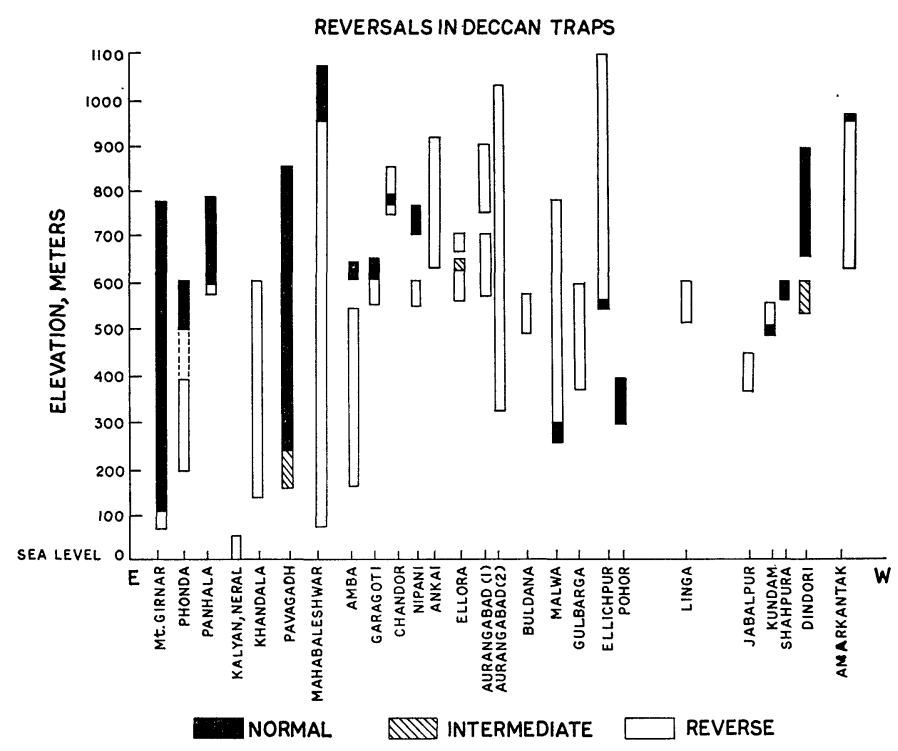

Fig. 6. Correlation of new field reversal with that from other areas in the Deccan trap country.

be near an elevation of about $650 \mathrm{~m}$, the normal rocks underlying the reverse ones below this elevation.

Wensink (1973) has divided the Deccan trap polarity reversal into four epochs, Nagpur (R), Pohor $(N)$, Deccan $(R)$ and Nipani $(N)$, the latter being the youngest one. In our opinion this classification is possible, however it needs to be strengthened by more detailed studies and radiometric dating of the samples. Figure 6 shows the nature of field reversal as observed at different locations in the Deccan traps. It is interesting to note that rocks with normal polarity underlying the reverse ones have been found mostly in the northeastern part of the Deccan traps exposure. General observations of field polarities in 


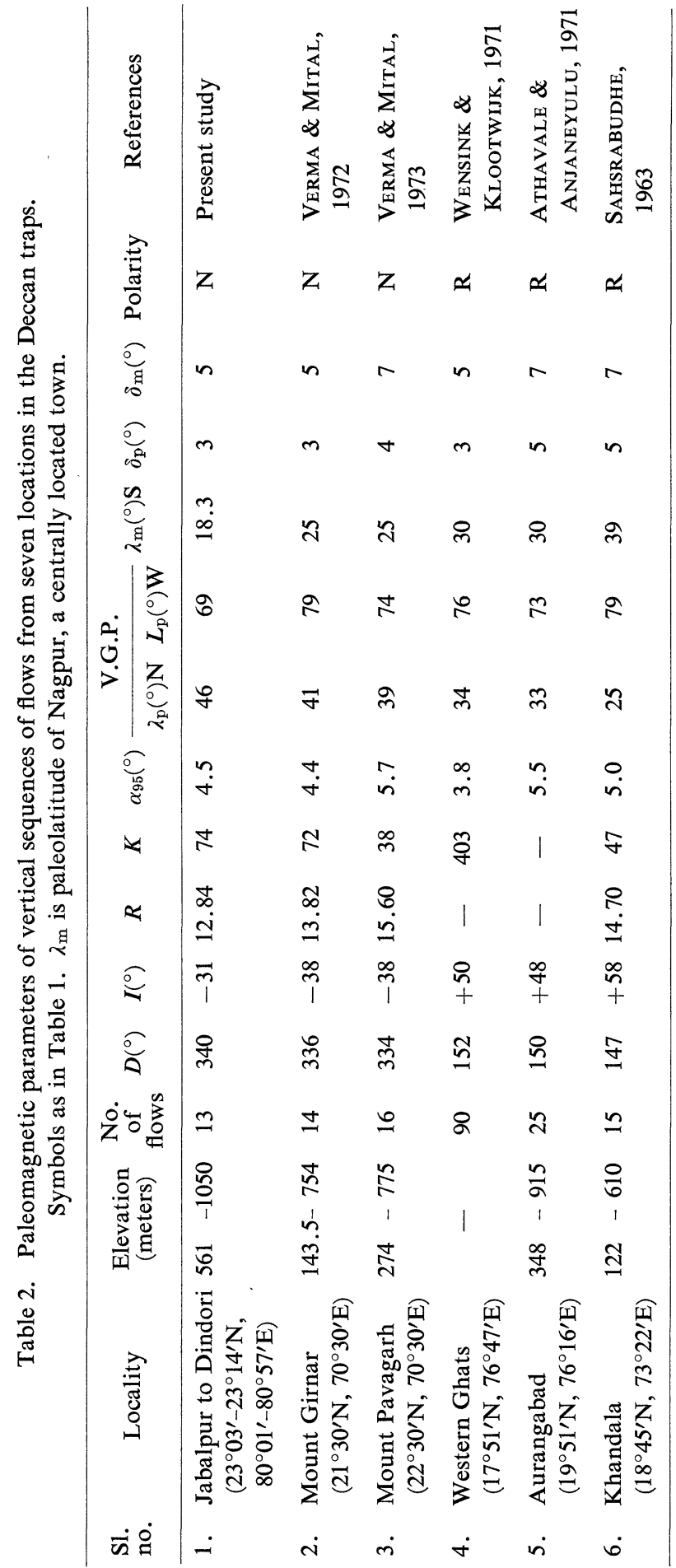


the Deccan traps suggest that there have been two periods of relatively long duration during which the field had a normal and a reverse polarity. However, there appears to be also small events of shorter duration which are associated with the longer periods.

A correlation of igneous activity represented by traps in Jabalpur to Dindori area with those from other parts is attempted. For this purpose mean directions and pole positions of five vertical sequences of normal as well as reverse polarity which have been studied in detail from Mount Girnar (Verma and Mital 1972), Mount Pavagarh (Verma and Mrtal 1973), Western Ghats near Poona (Wensink and Klootwijk 1971), Aurangabad (Athavale and Anjaneyulu 1971), and Khandala (SAHSRABUDHE 1963) are compared with those of normal polarity from the Jabalpur-Amarkantak region. Paleomagnetic Parameters of these sequences are given in Table 2. The corresponding mean pole positions are plotted in Fig. 7.

The poles from various sequences show a shift from about $25^{\circ} \mathrm{N}$ corre-

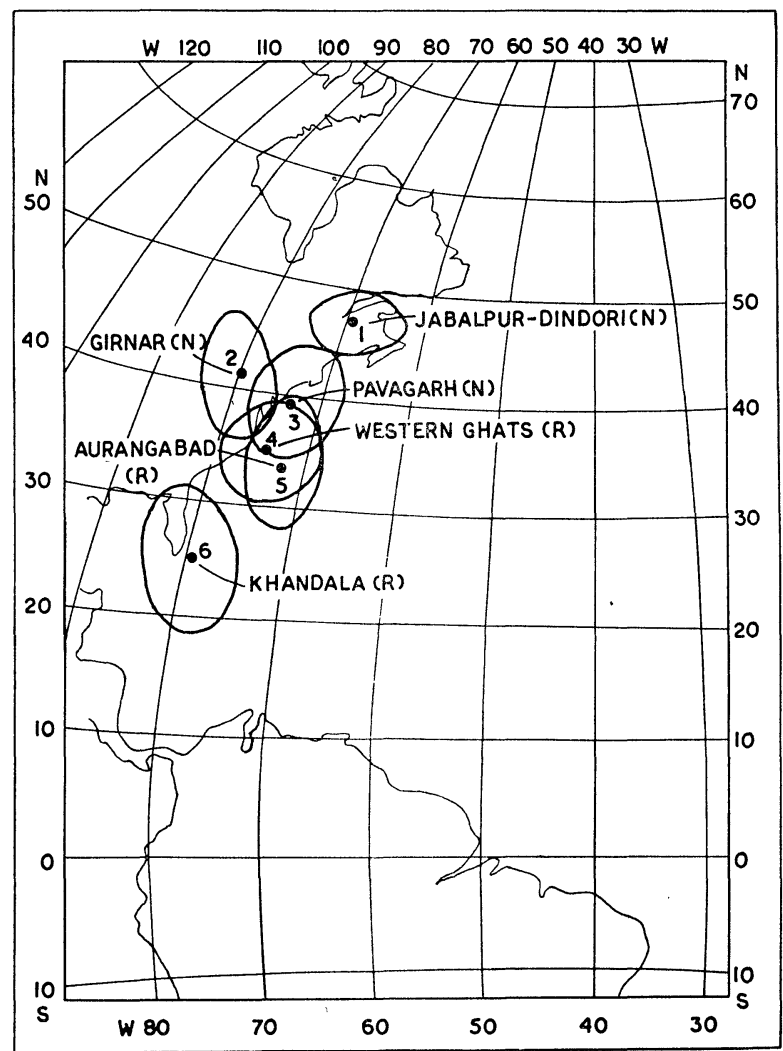

Fig. 7. Mean pole positions corresponding to mean direction of flows from vertical sequences of traps studied at Khandala, Western Ghats (near Poona), Aurangabad, Mount Girnar, Mount Pavagarh and Jabalpur to Dindori normal. 
sponding to the vertical sequence at Khandala, to about $46^{\circ} \mathrm{N}$ corresponding to the normal sequence from Jabalpur. The results of these studies can be interpreted in terms of drift of the Indian land mass during the period of entire igneous activity represented by the Deccan traps (VERMA and Mital 1973). For this purpose, the paleolatitude of Nagpur, a centrally located town in India has been calculated and is also listed in Table 2 . It is interesting to note that the paleolatitude of Nagpur has varied from $39^{\circ} \mathrm{S}$ to $18^{\circ} \mathrm{S}$ during the entire Deccan period. This represents a drift of the Indian land mass of the order of $21^{\circ}$ in latitude during the entire period of the Deccan trap eruptions.

We are thankful to Dr. E. Irving, Dr. W.B. Robertson, Mr. J. Roy and Mr. J. Park for critically reading the manuscript and their constructive suggestions. Thanks are due to Dr. Hari Narain, Director, N.G.R.I. for his keen interest in the study of paleomagnetism of the Deccan traps.

\section{REFERENCES}

Athavale, R.N., Paleomagnetism and tectonics of a Deccan trap lava sequences at Amarkantak, J. Geophys. Res., 75, 4000-4005, 1970.

Athavale, R.N. and G.R. Anjaneyulu, Paleomagnetic results on Deccan trap lavas of Aurangabad and their tectonic significance, Tectonophysics, 14, 88-103, 1971.

Bhimasankaram, V.L.S. and P.C. PAL, Paleomagnetic polarity transitions (?) during Deccan traps volcanism, J. Osmania University (Sci), Golden Jubilee volume 43, 43-61, 1968.

Clegg, J.A., E.R. Deutsch and D.H. Griffiths, Rock Magnetism in India, Phil. Mag. (8), 1, 419-431, 1956.

Cox, A., Geomagnetic reversals, Science, 163, (3864), 237-245, 1969.

Creer, D.M., A.C. demagnetization of Keuper Marls, Geophys. J. Roy. Astr. Soc., 2, 262, 1959.

Deutsch, E.R., C. Radhakrishnamurty and P.W. Sahsrabudhe, Paleomagnetism of Deccan traps, Ann. Geophys. (Paris), 15, 39-59, 1959.

Kono, M., H. Kinoshita and Y. Aoki, Paleomagnetism of the Deccan Trap Basalts in India, J. Geomag. Geoelectr., 24, 49-67, 1972.

McElhinny, M.W. and P.J. Burek, Mesozoic Paleomagnetic Stratigraphy, Nature, 232, 98102, 1971.

Pal, P.C., U. Bindu Madhav and V.L.S. Bhimasankaram, Early Tertiary geomagnetic polarity reversals in India, Nature Physical Science, 230, 133-135, 1971.

Pecherski, D.M., U.S.S.R. Academy of Sciences, Scientific works of the North East Complex Institute (SVKNEE), Magadam, 37, 58, 1970.

Sahsrabudhe, P.W., Paleomagnetism of geology of the Deccan traps, Proc. of Seminar on Geophysical Investigations of Peninsular Shield, Indian Geophysical Union, Hyderabad, 1963.

Verma, R.K. and G. Pullaiah, Paleomagnetic study of a vertical sequences of Deccan traps from Jabalpur, Bull. Volcanologique, Tome XXXV-3, 750-765, 1971.

Verma, R.K. and G.S. Mital, Paleomagnetic study of a vertical sequence of traps from Mount Girnar, Gujrat, India, Geophys. J. Roy. Astr. Soc., 29, 275-287, 1972.

Verma, R.K. and G.S. Mital, Paleomagnetic study of a vertical sequence of traps from Mount Pavagarh, Gujrat, India, Physics of the Earth and Planetary Interiors, 1973 (in press).

Wensink, H., Newer Paleomagnetic results of the Deccan traps, India, Tectonophysics, 17, 4159, 1973.

Wensink, H. and C.T. Klootwijk, Paleomagnetism of the Deccan traps in western Ghats near Poona, Tectonophysics, 11, 175-190, 1971. 